\title{
¿Castigo divino o Fenómeno natural? Mentalidad religiosa y mentalidad científica en Chile en torno al terremoto de $1822^{1}$
}

\author{
Gabriel Cid ${ }^{2}$ \\ Recibido: 18 de diciembre de 2013 Aceptado: 5 de enero de 2014
}

\begin{abstract}
Resumen
El artículo analiza, a partir del terremoto del 19 de noviembre de 1822 que sacudió a las provincias de Valparaíso y Santiago, el enfrentamiento entre las mentalidades religiosas y científicas en torno a la explicación de la catástrofe. El texto estudia tanto las prácticas religiosas que se llevaron a cabo por la población para aplacar la ira divina a la cual atribuía el origen del terremoto, como las críticas de la intelectualidad racionalista que explicaba la tragedia como un fenómeno natural sin vinculación con lo divino. En este sentido, el artículo reconstruye la polémica intelectual a la que dio lugar el terremoto en la opinión pública de la época y que animaron autores como Bernardo de Vera y Pintado, Camilo Henríquez y fray Tadeo Silva.
\end{abstract}

Palabras clave: Terremoto, Religión, Ilustración, Bernardo de Vera y Pintado, Tadeo Silva.

\section{Divine Punishment or Natural Phenomenon? Religious and Scientific Mentality in Chile Regarding the 1822 Earthquake}

\begin{abstract}
Focusing on the explanation for the earthquake of November 19, 1822 which affected the provinces of Valparaiso and Santiago, this article analyses the clash between scientific and religious mentalities. The text studies both religious practices to appease divine rage as a cause of the earthquake as well as rationalistic intellectual reasoning attributing the catastrophe to natural phenomena. The article reconstructs public opinion's intellectual debate in the voice of authors such as Bernardo de Vera y Pintado, Camilo Henriquez and Friar Tadeo Silva.
\end{abstract}

Key words: Earthquake, Religion, Enlightenment, Bernardo de Vera y Pintado, Tadeo Silva.

1 Una versión preliminar de este trabajo fue presentada en las III Jornadas de Historia de las Mentalidades y de la Cultura: Historia y religiosidad, Universidad de Concepción, octubre de 2011. El autor agradece a Vasco Castillo sus comentarios a una primera versión de este texto.

2 Chileno, Doctor (c) en Historia, Universidad del País Vasco. Programa de Historia de las Ideas Políticas en Chile, Universidad Diego Portales. E-mail: gabriel.cid@udp.cl 


\section{¿Castigo divino ou Fenômeno natural? Mentalidade religiosa e mentalidade científica no Chile em torno ao terremoto de 1822}

\section{Resumem}

0 artigo analisa, a partir do terremoto do dia 19 de novembro de 1822 que sacudiu as províncias de Valparaíso e Santiago, o enfrentamento entre as mentalidades religiosas e científicas em torno à explicação da catástrofe. 0 texto estuda tanto as práticas religiosas que se levaram em frente pela população para aplacar a ira divina à qual atribuía à origem do terremoto, como as críticas da intelectualidade racionalista que explicava a tragédia como um fenômeno natural sem vinculação com o divino. Neste sentido, 0 artigo reconstrói a polemica intelectual que deu lugar o terremoto na opinião pública da época e que animaram autores como Bernardo de Vera e Pintado, Camilo Henríquez e Frey Tadeu Silva.

Palavras chave: Terremoto, Religião, Ilustração, Bernardo de Vera e Pintado, Tadeu Silva.

Este artículo analiza, a partir del terremoto que sacudió a las provincias de Valparaíso y Santiago en noviembre de 1822, el enfrentamiento y debate entre las mentalidades religiosas y científicas en torno a la explicación de este suceso. Pocos escenarios resultan más atractivos para la historia de las mentalidades que las tragedias naturales, dado que en esas instancias límites los temores atávicos propios de la condición humana -como el miedo a la muerte, el miedo fundamental de acuerdo a Jean Delumeau (2002: 11)afloran con particular nitidez al enfrentarse de forma imprevista y dramática a las fuerzas de la naturaleza. Tales temores se plasman con frecuencia en prácticas culturales que evidencian las formas de decodificar la contingencia y hacer inteligible el mundo para una sociedad determinada. Aun cuando estos modos de darle sentido a la realidad exterior nunca son monolíticos, en épocas de tránsito histórico la emergencia del disenso en las pautas de comprender situaciones límites como las catástrofes naturales permiten también advertir la conflictiva construcción intelectual de nuevas formas de explicación de la relación entre el orden social y el natural. ${ }^{3}$

3 En este sentido, quizás uno de los hitos más significativos que devela esta situación en la historia intelectual de Occidente haya sido el terremoto de Lisboa de 1755. Esta catástrofe catalizó una discusión de alto vuelo filosófico -que involucró a intelectuales como Voltaire, Rousseau y Kant- en torno a problemas tales como la relación de las tragedias naturales y la moral, el sentido del sufrimiento, junto con el cuestionamiento del origen divino del terremoto. Sintetizando, lo que quedó en entredicho en adelante fue la idea de matriz leibniziana de que la humanidad vivía en el "mejor de los mundos posibles", cuestión que puso de relieve la crítica mordaz de Voltaire en textos como Cándido y, especialmente, en su Poema sobre el desastre de Lisboa, o examen del axioma 'todo está bien'. El terremoto 
Pocos períodos fueron tan dramáticos en cambios políticos y culturales como el paso del siglo XVIII al XIX en el mundo atlántico, período que Reinhart Koselleck (2004) ha designado como Sattelzeit, es decir, un "umbral de época", una época de inflexión donde se concentraría el tránsito desde el Antiguo Régimen a la modernidad. Esta mutación en las formas de aprehender la realidad política, social y cultural, también incluyó a Hispanoamérica. En efecto, y tal como ha argumentado Javier Fernández Sebastián (2011), en este mismo arco temporal se produce en el mundo iberoamericano una "época insólita de aceleración" en distintos niveles que dislocaron el universo conceptual alterando de forma inédita hasta entonces los "marcos de inteligibilidad social". El desajuste estructural propio de un mundo revolucionario, no tardó, por tanto, en hacerse sentir en el ámbito de las mentalidades.

Para el caso chileno, la crisis de la Monarquía hispánica, iniciada en 1808, significó, entre otras cosas, la inmersión del lenguaje de las elites al interior de la modernidad, una visión de mundo altamente racionalista donde lo sobrenatural, lo místico -y en algunos casos lo religioso- quedaba relegado a un plano inferior al considerarse modos de validar y hacer inteligible el mundo natural propios de una mentalidad premoderna, arcaica y anticientífica. Esta visión, sin embargo, no significaba la exclusión de la religión de lo público, pues en buena medida la llustración hispana fue una ilustración católica, como la llamó Mario Góngora (1998: 191). Con todo, y esto es lo relevante en la argumentación que se propondrá en las páginas que siguen, la explicación del mundo desde una clave numinosa propia de una cultura barroca dentro de la cual aún vivía la mayor parte de la sociedad, particularmente los sectores populares, comenzó lentamente a cuestionarse, siendo, en este sentido, el terremoto de noviembre de 1822 uno de los hitos más significativos que en sus polémicas intelectuales develan las tensiones del cambio cultural antes señalado.

Efectivamente, el terremoto de 1822 enfrentó con singular radicalidad esta nueva mentalidad racionalizante con aquella más masiva socialmente, la religiosa, que interpretaba fenómenos como aquel sismo como un castigo divino, siendo tal evento inteligible solo dentro de un sistema de referencias donde lo sobrenatural continuaba siendo un modo clave de validación y explicación de los sucesos naturales, lo que implicaba prácticas culturales colectivas ideadas para conjurar la furia celestial. Este artículo busca evidenciar no solo aquellas prácticas, sino también exponer las ideas que defendieron tales o cuales formas de entender un evento traumático como aquel terremoto, como

incentivó la reflexión de otros filósofos, como Immanuel Kant, quien en su breve Sobre el optimismo (1759), defendió la postura de Gottfried Wilhelm Leibniz, uno de los principales "damnificados por el terremoto de Lisboa". Al respecto véanse Álvarez, 2005; Dynes, 2000; Sanides-Kohlrausch, 2003; Shrady, 2009; Paice, 2008. 
lo reflejan las acaloradas discusiones entre Camilo Henríquez y Bernardo de Vera y Pintado, contra fray Tadeo Silva en la opinión pública de la época.

Evidentemente, un análisis como el aquí propuesto se sustenta en las herramientas metodológicas otorgadas por la microhistoria (Levi, 1996; Ginzburg, 1994; Serna y Pons, 2000). En efecto, al reducir la escala de observación y centrarse en un acontecimiento como el terremoto de 1822 no se busca solamente dar cuenta en detalle de este trágico suceso, sino, ante todo, utilizarlo como un mirador privilegiado en tanto evento catalizador de una serie de comportamientos colectivos y discursos que nos permiten descubrir y hacer evidentes problemas mayores, como el tránsito del Antiguo Régimen a la modernidad, la pervivencia de la cultura barroca tras la ruptura con la monarquía, o la eclosión de la cultura racionalista en el Chile decimonónico y su cuestionamiento a los excesos a los que podía dar lugar la religión. Es la invitación de las páginas que siguen.

\section{"Un concierto terrorífico": el terremoto de noviembre de 1822, el temor colectivo y la cultura barroca}

"Un concierto terrorífico". Con esas palabras el marino británico Richard Longeville Vowell (1831: I, 292), describió la noche del 19 de noviembre de 1822 en Valparaíso. Los sonidos percibidos en aquella noche, donde se mezclaban el ruido que antecedió al sismo, similar a "descargas de truenos subterráneos, como el de los torrentes que van arrastrando en su curso desenfrenado piedras de gran tamaño", sumado al "estruendo de las iglesias y otros edificios que se venían al suelo, los gritos de los habitantes despavoridos y los aullidos de los perros que pululaban por las calles", formaron un escenario macabro. El comentario del marino británico no fue aislado. En un informe dirigido al gobernador de Valparaíso José Ignacio Zenteno, Carlos Thurn habló sobre aquel "conjunto de circunstancias horrorosas que sumía al común de las gentes en un abismo de confusión, de terror y conflictos que no es permitido describir". Este pánico colectivo era comprensible si se consideraba la destrucción que había asolado al puerto principal del país. De acuerdo a su detallado oficio, el informante contabilizaba más de 60 muertos y un centenar de heridos. Edificios públicos como la casa de gobierno -donde estaba Bernardo O'Higgins, que resultó algo contuso- los cuarteles y la cárcel de la ciudad se habían venido abajo con el sismo, lo mismo que había acontecido con las iglesias de San Francisco y la Merced, lo que se sumaba a más de 700 viviendas particulares destruidas (Thurn, 1919: 189-193).

No solo Valparaíso estaba en ruinas. De acuerdo a lo que informaba El Mercurio de Chile (2-XII-1822), las localidades de Quillota, La Ligua y Casablanca también habían sido devastadas por el sismo, calculándose el 
número de muertos en cerca de 200. El terremoto, producido a las 22:30 y que tuvo una magnitud de 8,5 Richter con epicentro en Valparaíso, con una duración de cerca de 2 minutos y medio (Miquel, 1849: 106), ocasionó múltiples réplicas, las cuales siguieron observándose tras la noche del 19 de noviembre, llegando a contabilizarse, de acuerdo al detallado cálculo que realizó Felipe Castillo Albo, más de 150 temblores pequeños (El Mercurio de Chile, 2-XII-1822). ${ }^{4}$

Puesto que el sismo aconteció en la noche, el desconcierto y el pánico se acentuaron: "Los gritos y llantos de las mujeres y niños se oían por todas partes, y personas de todas las clases corrían casi desnudos por las calles, invocando a los santos por misericordia y protección", comentaba un bostoniano avecindado en Valparaíso (Niles' Register, 17-V-1823: 171). Ante el escenario de muerte y destrucción -lo que se sumó al temor a los saqueos que en efecto se llevaron a cabo esa noche (Longeville Vowell, 1831: I, 293)- y frente a la seguidilla de nuevas réplicas, tanto la Alameda en Santiago como los cerros de Valparaíso se convirtieron en improvisados puntos de reunión donde acamparon por días los atemorizados vecinos de ambas ciudades. En Valparaíso, el panorama empeoró, pues una inesperada lluvia en las noches posteriores hizo que la vigilia en la intemperie resultase más dramática (Miers, 1826: I, 393). Mary Graham (1824: 315) quedó impresionada ante la convivencia forzada y el poder nivelador que ejerció la catástrofe en la sociedad chilena. Esto se reflejaba en las innumerables "carpas y ramadas de los infelices" que tapizaban las laderas de los cerros, donde "ricos y pobres, jóvenes y ancianos, amos y criados, todos estaban confundidos y aglomerados en una intimidad que aun aquí, donde las diferencias de clases no son tan marcadas como en Europa, me pareció verdaderamente pavorosa". A tanto llegó la intimidad de los acampantes que de acuerdo a lo señalado irónicamente por el sueco Carl Bladh (1951: 65), ahí tuvieron su origen un gran número de matrimonios "que de otra manera no se hubieran concertado".

Ante este panorama, el horror era patente en cada mirada, donde se reflejaba "el horror que se apoderará de las almas en el juicio final", afirmaba Mary Graham (1824: 305-306). Si la devastación ocasionada por el sismo bastaba por sí misma para hacer del terror la sensación más evidente, la proliferación de rumores proféticos en la noche del terremoto acentuó la sensación de pavor en las multitudes, llegando a casos extremos. En Santiago, la noche del sismo, un sacerdote empuñando una figura de Cristo le preguntaba a la imagen a viva voz "si no era cierto haberle revelado que aquella noche se hundiría Santiago", vaticinio que "hizo abortar a una muchacha" producto del terror ocasionado, según afirmó Bernardo de Vera y Pintado (1823: 3).

4 Datos obtenidos del Servicio Sismológico Nacional: http://ssn.dgf.uchile.cl/seismo.html 
Las visiones premonitorias abundaron aquella noche en la capital. Una beata brindó una profecía aquella noche, recordó Vicente Pérez Rosales, lo que aumentó el pavor entre la población: "Ocurriósele a una santa monja decir a eso de las diez y media de aquella temerosa noche, que sabía por revelación que el temblor de tierra era precursor del fin del mundo, y que la hora del juicio final debía sonar a las once de la próxima mañana". La atmósfera que se formó ante estos nuevos y espeluznantes anuncios alcanzó visos de histeria colectiva: "A tan aterradora noticia, que se esparció por Santiago con rapidez eléctrica, contestó el pueblo saliendo de estampida hacia las plazas, plazuelas y paseos públicos, y sin darse razón de lo que hacía, el hombre ilustrado con el que no lo era, la señora y la simple fregona, todos, grandes y chicos, hicieron llevar, atropellados, a esos lugares de asilo tal copia de camas y colchones, que en un momento parte del tajamar, las plazas públicas y la reciente alameda se cubrieron de ellos". Como el anuncio apocalíptico no se cumplió en la mañana siguiente, prosigue Pérez Rosales, la interpretación religiosa se acomodó para anunciarle a la multitud que, gracias a las súplicas de las monjas, Dios "había perdonado al género humano otorgándole más años de vida" (Pérez Rosales, 1962: 61-62).

Por cierto, la vinculación entre profecías y catástrofes naturales no era extraña a inicios del siglo XIX chileno. Solo un par de años antes del suceso que analizamos, en julio de 1818, una monja de la capital había profetizado que un terremoto que duraría dos horas asolaría el país, decía El Argos de Chile (9-VII-1818), para luego afirmar con sorna: "Varias familias esperaron compungidas este suceso fatal, hasta que la luz del sol desvaneció las sombras del temor y la verdad tomó el lugar que le pertenecía". La religiosa, se mofaba el periódico, sencillamente había sido "chasqueada en sus primeros ensayos de profetisa".

En realidad, la interpretación de hechos como estos a la luz de un profetismo ex post, no era ajena a la cultura chilena, siendo natural en los marcos de una mentalidad donde lo sobrenatural era parte esencial del funcionamiento del mundo. La naturaleza misma parecía indicar el advenimiento de trastornos como el terremoto, para lo cual era preciso estar preparado para discernir las señales brindadas por ella. En Valparaíso, por ejemplo, los pescadores también aportaron con su acervo de visiones premonitorias, señalando que en las vísperas del terremoto se podía divisar en lontananza una gran luz sobre el mar: esta "permaneció un rato inmóvil; avanzó enseguida hacia la costa y dividiéndose en dos desapareció", señal que se atribuyó a una advertencia de la Virgen (Graham, 1824: 311). La luna al día siguiente del sismo, a eso de las 18:30 estuvo en fase de cuarto creciente, lo que causó cierta perturbación en la población, puesto que "no ha faltado quien por ignorancia atemorizase al pueblo por aquel momento, como si la luna ejercitase sobre los temblores un influjo igual al que ejercita sobre el movimiento periódico 
de las olas del océano", comentó el Ministro Joaquín Echeverría en informe a Bernardo O'Higgins (Gazeta Ministerial de Chile, 27-XI-1822). Con todo, el fenómeno más sorprendente fue la presencia al parecer de un meteoro que fue observado en la noche posterior del terremoto, cuyo resplandor produjo por un breve lapso de tiempo "una claridad igual a la de un crepúsculo ya claro". Tal suceso, como observó Longeville Vowell (1831: I, 295), "vino a aumentar en extremo la alarma de los aterrorizados habitantes". ${ }^{5}$

Los rumores proféticos y el discernimiento de señales de la naturaleza como premoniciones de las catástrofes reflejan un fenómeno mayor, que es la continuidad en la cultura popular de una visión del mundo físico indisociable del mundo religioso. En efecto, era evidente, de acuerdo a estas descripciones, que predominaba una visión de mundo providencialista, donde el mundo natural estaba sujeto a la voluntad divina, siendo las catástrofes naturales ordenadas por propósitos sobrenaturales inescrutables para la razón humana. Eso no significaba, en todo caso, que no se ensayasen interpretaciones sobre la causalidad de los fenómenos, y en virtud de esta visión de mundo, quienes proporcionaban la interpretación más plausible para la comunidad eran los sacerdotes. Estamos aquí en presencia de una continuidad notable con respecto al imaginario religioso del período colonial. Como ha argumentado Jaime Valenzuela en un excelente trabajo sobre las representaciones religiosas de las catástrofes naturales en el mundo colonial chileno, la Iglesia poseía una suerte de control simbólico e ideológico de las fuerzas naturales, descifrando la causalidad profunda de las tragedias -vinculadas en general a la expresión de la ira divina ante los pecados de la comunidad-, permitiéndole de esta forma conformarse en "un baluarte psicológico para encontrar una explicación al caos y a la desolación, y para entregar las pautas de acción e iluminar el camino que condujese a reencontrar la gracia divina, devolver la esperanza y, en definitiva, volver al orden" (Valenzuela, 2006: 48).

La imaginería religiosa tuvo un papel central en el proceso de reordenar el caos desde la perspectiva de la devoción católica tradicional. Esto no solo en el sentido de la omnipresencia de cruces y rosarios como amuletos indispensables en un trance como el vivido en la noche del 19 de noviembre, sino en otras facetas. Así, por ejemplo, en Valparaíso tras el terremoto se extendió el rumor de que sobrevendría otro mayor, hecho que causó gran espanto entre el bajo pueblo quien corrió a buscar refugio en los cerros. Pero al no producirse la profetizada hecatombe, la religiosidad popular atribuyó tal hecho a la intercesión de Nuestra Señora de Quintero, cuya imagen co-

5 Para Felipe Castillo Albo, aquella "bola de fuego que dio bastante luz", podría atribuirse más bien a erupciones volcánicas provocadas en la misma noche del sismo. Véase Cid, 2009: 290. 
bró especial relevancia en aquellos días, afirmó Mary Graham (1824: 310), acudiendo "en aquella espantosa noche todas las mujeres de la vecindad y con clamores y sollozos imploraron su protección, mesándose los cabellos y prodigándole los más tiernos nombres", hecho que no impidió, sin embargo, que días más tardes la imagen se rompiera y quedara decapitada con las réplicas. Otras imágenes que adquirieron relevancia en aquellos días de terror colectivo fueron los improvisados grabados de San Hermenegildo, el santo de los terremotos, que fueron vendidos en Santiago al elevado precio de 2 reales. El grabado poseía "una oración del mismo santo, debajo de la cual se podía leer una afirmación del obispo, que aquel que colocaba esta oración en su pieza y la leía tres veces al día, no iba a sufrir en el terremoto", observó Carl Bladh (1951: 59).

Las prácticas devocionales espontáneas fueron acentuadas con el proceso de culpabilización que fue de la mano de la intensa actividad de los sacerdotes, que por medio de la prédica colectiva compungían al aterrado auditorio. El clero nacional, observaba fray Tadeo Silva, "viendo la conmoción general, los efectos de la compunción, las penitencias aflictivas y las lágrimas de arrepentimiento con que hasta los más viciosos explicaban el interno dolor de sus pecados y clamaban por la confesión sacramental", se vio en la necesidad de hacer frente a la demanda espiritual de la comunidad. "En consecuencia de este aviso del Espíritu Santo hizo resonar el sacerdocio la trompeta de la divina palabra en las calles y lugares públicos, convidó al pueblo a llorar sus pecados, a afligir la carne, y a borrar las culpas por una sincera conversión. Exhortaciones fervorosas, misiones sagradas, confesiones frecuentes eran sus ejercicios cotidianos; se tomó por asunto de casi todos los discursos evangélicos combatir el vicio, y hacer ver al pueblo con los hechos del testamento antiguo y los oráculos de los Santos Profetas, que las causas de las pestes, guerras y terremotos eran ordinariamente los pecados". De este modo, añadía el sacerdote, si los feligreses deseaban "que parasen los vaivenes de tierra, que aún duraban, el medio más oportuno era una verdadera compunción" (Silva, 1823a: 6-7).

Ante esto, la compulsión por confesarse entre los feligreses alcanzó ribetes dramáticos. Entre los gritos tradicionales de "¡Misericordia!", Vicente Pérez Rosales (1962: 61) pudo observar en Santiago "a un asustado sacerdote que pugnaba por desprenderse de una mujer que, asida a su sotana, se arrastraba de rodillas implorando a gritos la absolución de los pecados que en alta voz le confesaba". En Valparaíso, asimismo, los espantados pobladores que pernoctaban en los cerros "se reunieron en grupos alrededor de los padres, confesando en alta voz sus pecados y rezando el rosario con gran devoción" (Longeville Vowell, 1831: I, 294).

En este ambiente de mortificación, penitencia y culpabilización colectiva, la necesidad imperiosa de obtener la absolución de los pecados ante la inmi- 
nencia de la muerte, llevó repentinamente a los feligreses a intentar regularizar su vida de acuerdo a los cánones religiosos. Así, por ejemplo, en aquellos días se reunieron matrimonios disueltos y aumentaron explosivamente las nupcias con los repentinos "enlaces matrimoniales de tantos concubinarios". 6 Los artesanos abandonaron las chinganas allende el Mapocho, mientras que otros tantos dejaron las casas de juego, "donde se hacen mil trampas, se cometen abominables excesos, y se reducen a los que las frecuentan a ser indefectiblemente unos ladrones para mantener este vicioso ejercicio". Asimismo, cesaron "los bailes escandalosos, donde las jóvenes se enredan en amistades, que después hacen gemir a sus padres, y los hombres disolutos se atreven a cuanto pueden en ocasión tan oportuna", observaba con gran complacencia fray Tadeo Silva (1823a: 9). Por cierto, no solo el clero patrocinó las prácticas edificantes destinadas a rectificar las conductas pecaminosas que supuestamente habían originado el terremoto. El mismo Gobierno decretó el 20 de noviembre la cesación de funciones teatrales y diversiones públicas, puesto que era preciso " $\mathrm{y}$ justo que todos los habitantes no tengan un embarazo que les distraiga del objeto de elevar sus súplicas para aplacar la ira divina" (Gazeta Ministerial de Chile, 27-XI-1822).

Dado que para buena parte de la comunidad afectada por el terremoto resultaba claro que éste era la justa retribución divina ante sus pecados, las procesiones y penitencias fueron quizás las formas más claras en que se reflejó la culpabilización colectiva. Las procesiones, entendidas como mecanismos rituales de intercesión frente a la divinidad, tuvieron en este contexto catastrófico un escenario privilegiado como práctica devocional. En efecto, los usos expiatorios del espacio público representaban instancias cruciales para plasmar la expresión rogativa de la comunidad. Según observa Jaime Valenzuela (2006: 55-56), por medio de estas, una de las plasmaciones más evidentes de la pervivencia de la devoción barroca colonial, se volcaba en las calles "la exteriorización colectiva y corporativa de la piedad" como un medio de manifestar el arrepentimiento y rechazo a la pecaminosidad por medio de la auto-mortificación. Prontamente tras el terremoto comenzaron estas actividades. En Santiago, por ejemplo, desde la misma madrugada del día 20 y especialmente en los días siguientes se podía observar por las calles a las mujeres de la capital, particularmente a las jóvenes, "vestidas de blanco, descalzas, con la cabeza descubierta, sueltos los cabellos y con crucifijos negros", recorriendo las calles "cantando himnos y letanías, precedidas de las órdenes religiosas" (Graham, 1824: 311). Pocos testigos sintetizaron mejor la atmósfera de compunción religiosa y su plasmación en veneración de imágenes, rogativas, procesiones y prédicas públicas tras el terremoto

6 El mismo fenómeno se puede observar tras el terremoto de 1730 (Palacios Roa, 2009: 1516). 
que María Juana de Eyzaguirre. En carta al exiliado sacerdote José Alejo Eyzaguirre, describía las múltiples actividades penitenciales de la población chilena en los siguientes términos: "La gente está muy atemorizada; se están haciendo rogativas de la Merced; salió Nuestra Señora en el trono; está abajo, se está siguiendo su novena por la mañana; de Santo Domingo se han llevado a Nuestra Señora al Tajamar a una casa; sale el rosario y después hay sermón del Padre [Tadeo] Silva, concurre mucha gente; también hay misión en la Domínica, en San Diego; en todas partes es afuera de las iglesias en la plazuela de las Monjitas Recoletas también hay misión; [José Manuel] Irarrázaval es el de la plática; dio principio con el primer sermón y han seguido los clérigos; por las calles quedan rezando la viacrucis los Padres Franciscanos y de la Merced; a todo concurre mucha gente de toda clase", sentenciaba la devota mujer (cit. Quiroz, 1987: 124-125).

En Quillota las festividades con ocasión de San Martín, el patrono del pueblo, la plaza se encontraba atestada de las tradicionales ramadas y su correlato de "jaranas, borracheras, bailes, música, máscaras, en suma una escena de disipación, o mejor dicho de libertinaje". No obstante, el terremoto significó una alteración radical en la conducta de los lugareños, que pasaron del festín a la devoción más extrema. En efecto, "en lugar de las canciones y de los sonidos del rabel alzóse un grito de ¡Misericordia! ¡Misericordia! Todos se golpeaban el pecho y se postraban en tierra." Algunos fueron más allá, y tejiendo coronas de espinas "las ponían en sus cabezas y las oprimían hasta que la sangre les corría por el rostro" (Graham, 1824: 312). La devoción extrema de la autoflagelación reapareció en medio del ambiente de pavor colectivo, constituyéndose en una de las prácticas religiosas más chocantes para muchos observadores. En Valparaíso se podía ver tras el terremoto que "algunos hombres se azotaban desnudos de la cintura arriba y se golpeaban con manojos de espinas hasta que sus espaldas laceradas manaban sangre" (Longeville Vowell, 1831: 294), mientras que en la localidad de Renca la práctica llegó a un extremo macabro, puesto que uno de los penitentes murió "con el pulmón reventado" en medio del fragor de la autoflagelación (EI Mercurio de Chile, 16-XII-1822).

Prácticas religiosas tan extremas sirvieron como catalizador de las discusiones en torno a la causalidad del terremoto, pero también en la medida que se constituyeron en hechos clave para hacer evidente la tensión entre el ideario racionalista al que adscribía parte importante de la emergente intelectualidad republicana y las prácticas devocionales populares, que evidenciaban el arraigo y la permanencia a inicios del siglo XIX de la devoción barroca de fuerte impronta colonial (véase Valenzuela, 1995). 


\section{¿Castigo divino o fenómeno natural? La polémica intelectual en torno al terremoto}

Describiendo el terremoto, El Mercurio de Chile, editado por Camilo Henríquez, procedía no solamente a referir sus devastaciones en la población capitalina, sino también a dar una explicación de sus causas. La catástrofe, apuntaba la descripción, había sido originada "por una tempestad subterránea, probablemente originada de la inflamación de inmensa cantidad de hidrógeno". Dado que Santiago estaba a una considerable altura por sobre el nivel del mar, "conjeturamos que el camino que siguió el gas inflamado, está a inmensa profundidad o distancia de la superficie". A estas consideraciones se agregaba que "los temblores no son frecuentes, como podían ser por la abundancia de metales preciosos y de azufre, de sulfates, de hulla, de hierro, etc. que encierra en sus entrañas el opulento Chile" (El Mercurio de Chile, 2-XII-1822). El tono altamente cientificista para explicar la causalidad de la tragedia desde las páginas del periódico fue potenciado cuando en ese mismo número se publicaron las observaciones meteorológicas de Felipe Castillo Albo, donde se consignaba, junto a cada sismo acaecido desde la noche del 19 de noviembre, una breve descripción de su duración, la temperatura y la presión atmosférica que lo acompañó.

En la misma entrega del periódico Bernardo de Vera y Pintado, de forma anónima y haciéndose pasar como teólogo, asumió la defensa de la causalidad de la catástrofe desde una perspectiva científica. Los terremotos en Chile tenían una periodicidad que los hacía ser fenómenos esperables en promedio cada 90 años. En este sentido, no tenían nada de extraño a la realidad física del país, y por tanto su regularidad podía explicarse desde un punto de vista estrictamente científico: "la naturaleza -observaba el santafesino- no cambiará su curso, ni dejará de conmoverse la tierra en las épocas en que por el orden de sus leyes y construcción se dispone la material causa de los terremotos". Establecido este punto, Vera y Pintado agregaba que entonces era "la fermentación de los combustibles que abrasan lo interior de la tierra, el aire encerrado en ella, dilatado por sus incendios, y que hace considerables esfuerzos para ensancharse y huir el agua reducida a vapores y que eleva con prodigiosa fuerza cuanto se opone a su expansión; he aquí los agentes que originan el terremoto", concluía tajante (El Mercurio de Chile, 2-XII-1822).

El establecimiento de la causalidad estrictamente natural del terremoto tenía una arista teológica de la más grande importancia. Si Dios no había tenido nada que ver con la catástrofe, como argumentaba Bernardo de Vera y Pintado, entonces resultaban inútiles los esfuerzos por conjurar por medio de actos devocionales extremos la inexistente furia divina. Era erróneo, planteaba el santafesino con ironía, concebir "un Dios que tenga el placer de haber fijado cierto número de años para levantarse de mal humor como 
los hombres ideáticos, y complacerse en ver por un momento desgarrar sus carnes a los que no fueron despedazados por el terremoto" (El Mercurio de Chile, 2-XII-1822). Eran prácticas devocionales como los penitentes las que estaba criticando abiertamente Vera y Pintado, y lo mismo hizo Camilo Henríquez cuando afirmó que "el terror, que se apodera de la imaginación despóticamente, lleva al exceso a los débiles e ignorantes", sorprendiéndose del retorno de los penitentes, una práctica que "la cultura de las ciencias con los progresos de la civilización había desterrado, años ha". Ese "espectáculo horrible y antievangélico" era una de aquellas prácticas propias de la "edad media, muy desacreditada por los mejores médicos, y que por otra parte no favorece a la decencia pública". La paradoja que se presentaba ante los ojos de la sociedad chilena era evidente para Henríquez: la persistencia -en un contexto postrevolucionario que se suponía inserto en la lógica del progreso, la civilización y la ciencia- de una práctica que incluso la misma llustración dieciochesca había desterrado (El Mercurio de Chile, 2-XII-1822). ${ }^{7}$ En realidad, tanto Henríquez como Vera y Pintado eran hombres cuyas reflexiones en torno a la sociedad pueden filiarse con el pensamiento iluminista del siglo XVIII, donde el eclecticismo filosófico racionalista y la adhesión progresiva a las ciencias como mecanismo de validación de los saberes permitía cuestionar visiones de mundo donde lo sobrenatural y la superstición aún permanecían vigentes (Jocelyn-Holt, 2001: 105-112).

Fueron precisamente estos problemas expuestos por El Mercurio de Chile, a saber, la inexistente conexión entre Dios y los fenómenos naturales, y por tanto la ineficacia de ciertas prácticas devocionales a este propósito, las que gatillaron una intensa polémica intelectual con fray Tadeo Silva, que se trasladaron al espacio de los panfletos. Silva criticó duramente los postulados de El Mercurio de Chile, particularmente los escritos de Bernardo de Vera y Pintado en un opúsculo que tituló Aviso que da al pueblo de Chile un filósofo rancio, texto al cual respondió brevemente el santafesino con su Palinodia del consolador en satisfacción al filósofo rancio. La polémica deambuló entre problemas teológicos, culturales y científicos, que develan el conflicto entre mentalidades propio del tránsito de la tradición a la modernidad al que hemos hecho alusión al inicio de este trabajo.

Un primer momento dentro de este debate, que ya en parte hemos descrito y citado porciones de su argumentación, se refiere al establecimiento de un origen puramente natural en la causalidad del terremoto, desvinculándolo así de un supuesto origen moral. Era lo que sostenían, entre otros, Bernardo de Vera y Pintado, Felipe Castillo Albo y Camilo Henríquez. El terremoto chileno

7 Henríquez hacía alusión a la supresión de la práctica de los penitentes decretada por Carlos III en real cédula de 20 de febrero de 1777. 
"ha guardado el período regular con que ordinariamente acontecen estas revoluciones en el globo terrestre", apuntaba Vera y Pintado, para añadir que "desde los Andes hasta el Japón, desde Islandia hasta las Molucas las entrañas del globo perpetuamente se despedazan por incendios que obran sin cesar con más o menos violencia. Causas tan poderosas precisamente han de producir efectos que influyan en la masa total de la tierra", siendo Chile, en este caso, una víctima natural de la "furia de los elementos". Así, se podía concluir tajante que eran "las inflamaciones de las materias combustibles, o sea el fuego eléctrico la causa de los terremotos" (El Mercurio de Chile, 2-XII-1822).

Para fray Tadeo Silva, quien fundaba su argumentación exclusivamente en referencias bíblicas, las explicaciones científicas no podían disociar, a riesgo de ser erróneas, el orden natural del orden divino, en tanto este supeditaba al primero de acuerdo a sus designios trascedentes que resultaban generalmente inescrutables a la razón humana. Por tanto, si bien las sustancias químicas que permitirían explicar científicamente las causas de los terremotos eran naturales - ¿qué sustancia no lo era?, retrucaría con ironía posteriormente Vera y Pintado (1823: 6)-, no era menos cierto que "muchas veces se inflaman esas mismas materias por el soplo de una providencia especial, que las pone en acción, o para castigo, o para prueba, o para otros fines solo comprensibles al Altísimo". Incluso, aún si Dios no enviaba explícitamente los terremotos, en un sentido positivo, el mismo hecho que los permitiera implicaba en sí el origen celestial de los fenómenos físicos, observaba el clérigo: "Es verdad que muchas veces deja Dios en libertad por su voluntad permisiva a esas causas naturales, para que según las leyes de acción y reacción produzcan los espantosos fenómenos de terremotos, pestes de sequedades y de muertes repentinas; pero entonces la misma voluntad de no impedir los perniciosos efectos de estas causas es una voluntad de castigar con estas permisiones tan funestas a la miserable humanidad" (Silva, 1823a: 12, 14-15).

Un segundo momento de esta polémica se enmarca dentro del argumento expuesto por Bernardo de Vera y Pintado, según el cual la desvinculación religiosa de la causalidad del terremoto tenía un trasfondo teológico más importante. De acuerdo a su razonamiento, era erróneo atribuir el origen de la catástrofe a la ira divina, puesto que por su naturaleza "Dios no puede enojarse. Él es inmutable, siempre dichoso y sin alteración. La cólera es una pasión de los débiles morales". Establecido este punto, se debía considerar otro no menos importante, que era la vinculación de la ira divina con los pecados humanos, siendo en este sentido las catástrofes naturales desde una lectura providencialista el resultado de la justa retribución celestial a los extravíos de la humanidad. Desde una perspectiva teológica, la lectura del terremoto en esta clave presupondría el conocimiento de los designios divinos, lo cual estaba ajeno a las capacidades humanas: "¿Quién tiene el derecho 
de interpretar a Dios y pretender que ha querido ostentar su justicia y no su misericordia? ¿Qué razón hay para que el amago de esta catástrofe general se impute a una determinación severa del Cielo, más que el tabardillo, o el dolor de muelas?" (El Mercurio de Chile, 16-XII-1822).

Contrariando estas posturas, fray Tadeo Silva se encargó de desmontar el argumento de los "ilustres defensores del naturalismo", a quienes denominó sin ambages como "emisarios del demonio". En primer término, el sacerdote sostenía que Vera y Pintado erraba palmariamente desde una perspectiva teológica, puesto que interpretaba erróneamente las Escrituras, puesto que la ira divina era solo una alegoría, una forma de figuración literaria de "los efectos que produce su diestra omnipotente", sin que esto implicara "imaginar en su ser inmutable las pasiones que los producen en los hombres". Más importante resultaba la refutación a la segunda aseveración que el publicista santafesino extraía de su argumento, esto es, que era imposible conocer los designios divinos, por tanto, resultaba un tanto fútil atribuir los terremotos a la cólera celestial. En realidad, sostenía Silva, aun cuando era efectivo que los propósitos celestiales resultaban con frecuencia inescrutables a la razón, sí era posible conocer algunos lineamientos generales de la voluntad divina. Pero para conocer esto, no se podía seguir la línea argumental de los "filósofos modernos", puesto que "la razón no puede descubrirles los designios que se prefija la Divina Providencia en sus ideas sempiternas". La verdad no solo ya había sido revelada escrituralmente y por la tradición patrística, sino que no se podía arribar a esta disociando razón y fe, el error nuclear de la filosofía especulativa dieciochesca cuyos ecos se manifestaban en esta misma polémica. Así, si bien los sabios del siglo podían en algunos casos mediante la indagación racionalista inferir las causalidades de algunos fenómenos físicos, incluso de las tragedias naturales, "nunca encontrarán en sus investigaciones las causas morales que obligan a Dios a hacerlos, o permitirlos; éstas solo pueden saberlas las Sagradas Escrituras, donde el Todopoderoso nos ha descubierto sus designios". Y lo que descubría un examen minucioso de las Escrituras, concluía, era que "pestes, hambres, guerras, inundaciones, terremotos, son efectos morales de los delitos de los pueblos" (Silva, 1823a: 16-17).

Finalmente, Silva afirmaba que asumir que los terremotos eran "efectos inevitables de causas naturalísimas, y que no son destinados por la mano del Todopoderoso para castigo de los crímenes" era uno de los peores errores que se podían defender, en especial por las implicancias morales que se seguirían de aceptar este axioma. En efecto, esto resultaba perjudicial, "porque una vez que las gentes se penetren de estas ideas halagüeñas, se adormecerán en los vicios, y las que escapen del riesgo que tuvieron a la vista, no pensarán en enmendar sus delitos, que suponen no tener alguna conexión con estas calamidades deplorables; de donde se seguirá, que vendrá a su tiempo otra 
pena más dura, que haga ver a los crédulos que el pecado es la causa ordinaria de estos daños, y que no debieron creer a consoladores lisonjeros", enfatizaba (Silva, 1823a: 11). Así, resultaba claro para Silva que Chile había sufrido el terremoto como consecuencia de sus pecados.

¿Cuáles eran estos pecados nacionales que explicaban la tragedia del 19 de noviembre de 1822? Había varios puntos que Tadeo Silva (1823a: 29) señalaba como indicadores de una creciente pecaminosidad colectiva entre sus compatriotas que justificarían la ira divina. Entre estos se contaban "los libros irreligionarios, que corrompen la moral, el desprecio del sacerdocio, el lujo excesivo que destruye las familias, la arrogancia de muchos orgullosos fariseos, la mofa de las prácticas religiosas, y otros vicios que omitimos referir". No resulta sorpresiva la argumentación si se piensa por una parte que es precisamente en esta época donde comienzan a publicarse las primeras ideas en torno a la necesidad de llevar a cabo una reforma eclesiástica en el país, tomando como modelo el Río de la Plata, transformaciones que finalmente se implementarán en 1824 (Castillo, 2005). ${ }^{8}$

Pero sobre todo, la mención a la infiltración de ideas irreligiosas en el país - dentro de las cuales este mismo debate es parte- resultaba un punto crucial para Tadeo Silva, que evidenciaba la eclosión embrionaria de una nueva atmósfera intelectual. De hecho, una muestra clara de esta situación es la polémica que lo enfrentó nuevamente a Camilo Henríquez, por los comentarios vertidos por este último desde las páginas de El Mercurio de Chile (13-III-1823), donde alabó a autores como Rousseau, Montesquieu y Voltaire, llamándolos "apóstoles de la razón". Silva respondió con un folleto cuyo título ahorra mayores comentarios, Los apóstoles del diablo. Allí, entre otras cosas, mostraba su extrañeza frente a la situación que "el Estado de Chile cuya ley fundamental ordena a las primeras potestades, que no permitan correr ninguna doctrina contraria a la Religión de Jesucristo, se tolere el curso libre y público de esas infames producciones". Más aún, si Suiza había proscrito a Rousseau y Francia había hecho lo mismo con Voltaire, resultaba sorprendente que "Chile sufra indiferente la venta pública de todos sus escritos perniciosos, y el Periodista del Gobierno [Henríquez] los recomienda con audacia" (Silva, 1823b: 19-20).

Pero las ideas irreligiosas iban acompañadas para Silva de otro concepto que resultaba fundamental para explicar este nuevo escenario de incredulidad: la tolerancia. En efecto, de acuerdo a lo expuesto en Los apóstoles del diablo, la "tolerancia infernal" que se comenzaba a promover en el país por

8 Para la reforma eclesiástica en el Río de la Plata, véase Di Stefano (2004: 193-214). Los lineamientos generales de esta reforma fueron defendidos desde las mismas páginas de $E /$ Mercurio de Chile, en sus ediciones de 23 y 31 de agosto de 1822 . 
la "secta anticatólica" solo deseaba ver en el país "una Mezquita de Moros al frente de una Catedral, una Sinagoga, o una Pagoda al lado de cada Parroquia, una Logia o un templo de Luteranos cerca de cada Convento, para que cada cual vaya donde guste a los oficios religiosos" (Silva, 1823b: 2-3). Por cierto, Silva no fue el único quien vio en estas primeras ideas de tolerancia, en especial frente a la comunidad protestante de Valparaíso, una de las claves para comprender el juicio divino que se había manifestado en el terremoto del 19 de noviembre.

Según recordó el sueco Carl Edvard Bladh (1951: 59), "los curas y monjes en congregaciones públicas echaron crudísimas maldiciones sobre los herejes, quienes por la emancipación igualmente maldita habían obtenido permiso para vivir entre los fieles, y debido a lo cual terremotos y otras plagas habían caído sobre el país como prueba de la ira de Dios". Su comentario no fue aislado, puesto que John Miers (1826: v. I, 394) sostuvo que el terremoto y las réplicas fueron interpretados por la comunidad como "una señal de la furia divina" frente a la pecaminosidad de los chilenos, la conducta de los mandatarios y, especialmente, debido al "crimen de permitir que los herejes ingleses contaminaran el país". La idea de que el origen del terremoto debía buscarse en la política de tolerancia hacia los protestantes promovida por el gobierno de O'Higgins -a la que nos referiremos más adelante- se extendió rápidamente en la noche del terremoto, especialmente en Valparaíso, donde residía la mayor cantidad de extranjeros vinculados a esta fe. Así, de acuerdo a lo que refiere Benjamín Vicuña Mackenna (1976 [1861]: 403, n.), la misma noche del 19 de noviembre "comenzáronse a reunir en las callejuelas de que entonces se componía Valparaíso, grupos siniestros que vociferaban que era preciso matar a todos los gringos para aplacar la ira de Dios". Esta idea popular, potenciada por las continuas prédicas del clero, encontró freno cuando el mismo Director Supremo, residente entonces en el puerto, evitó mediante la fuerza pública cualquier atentado contra los protestantes. En algún momento pareció algo verosímil que si O'Higgins "no hubiera dispersado estas concentraciones inmediatamente, el pueblo bajo hubiera caído en el fanatismo y una noche de San Bartolomé hubiera podido ocurrir en Chile", como comentó Carl Bladh (1951: 59).

Como sabemos, desde la perspectiva de una cultura popular tradicionalista -aunque tampoco resulta privativa de ésta-, las catástrofes por lo general van de la mano con la necesidad de redireccionar a un "otro" estereotipado la causalidad de las tragedias, convirtiéndose estos grupos con frecuencia en "chivos expiatorios" que permiten sintetizar en sus personas los males que ocasionan las catástrofes naturales (Burke, 1978: 177). El mismo desconocimiento relativo que tenía la sociedad chilena de las comunidades protestantes a inicios del siglo XIX (sumado a la tradición inquisitorial) permitía estereotipar malignamente a quienes no compartían ni los mismos rasgos fenotípicos, 
ni la lengua, ni las costumbres ni menos la religión. Aspectos como estos, por ejemplo, explican en parte la pervivencia de mitos extendidos entre los sectores populares, tales como que los protestantes tuviesen una cola, un "apéndice satánico" que evidenciaba la intrínseca malignidad de su herejía, según refiere Samuel Haigh (1831: 143). ${ }^{9}$

En realidad, el gobierno de O'Higgins buscó establecer relaciones cordiales con los protestantes avecindados en el país, lo que desde la perspectiva católica pronto generó recelos que explosionaron en el terremoto de 1822 y que explican comportamientos como los antes descritos. Efectivamente, en 1819 un grupo de protestantes levantó al Director Supremo una petición, solicitándole la autorización para la compra de terrenos en Santiago y en Valparaíso para llevar a cabo ritos funerarios acordes a su doctrina, puesto que hasta ese entonces quienes morían, o debían abjurar de su fe para ser enterrados cristianamente, o simplemente quedar expuestos a "ser perturbados después del entierro y expuestos en la playa en el puerto de Valparaíso".

O’Higgins autorizó la petición de la comunidad protestante, señalando que "estos actos en nada contrarían los de nuestra Religión Católica. Ellos se han conducido hasta el día con la mejor política, sin mezclarse directa ni indirectamente en materias de creencia" (Gazeta Ministerial de Chile, 18XII-1819).

Hechos como este reflejaban una permisividad que desde la perspectiva católica no podía ser tolerada, si se consideraba el carácter confesional del Estado chileno. Así, por ejemplo, ya en enero de 1820 un conjunto de sacerdotes -entre los cuales se contaba fray Tadeo Silva- comentaba el accionar del gobierno hacia los protestantes, afirmando que proceder con tolerancia en esta situación significaría permitir una forma de propaganda velada del protestantismo, lo que induciría a las personas irreflexivas y a los irreligiosos a adherir a su fe (Archivo Nacional, Fondo Ministerio del Interior, Vol. 22, fs. 91-95). Con todo, para los propósitos de la argumentación que aquí se propone resulta más esclarecedor el informe que publicó solo semanas antes del terremoto de 1822 el sacerdote José Javier de Guzmán sobre este problema. El informe era categórico en sostener que permitir el culto de otras religiones en el país, en particular los protestantes, significaría para el

9 Benjamín Vicuña Mackenna recordaba en 1865 desde el Congreso, precisamente en el escenario del debate en torno a la libertad de cultos, la imagen tradicional que reinaba sobre judíos y protestantes a inicios del siglo XIX: "Yo también he sido intolerante, como todos los que nacen en nuestro suelo. Yo era de los niños que iban a las procesiones a escupir a los judíos, y cuando divisaba un protestante por la calle corría con mis hermanos a esconderme en el último patio de mi casa, porque esas son las ideas que flotan en la cuna de todos los niños que nacen bajo los techos de la católica capital de Chile". Vicuña Mackenna (1939: 21). 
país no solo "juntar las banderas de Cristo con las de Satanás, y los rayos de la luz con las tinieblas", sino que por su misma dinámica anticatólica, la tolerancia terminaría destruyendo el país desde sus cimientos: "El detestable libertinaje, con sus seductivas, sensuales y halagüeñas opiniones atraería a sus ideas una multitud de jóvenes incautos, y los haría disidentes, y apóstatas de nuestra Religión. Debilitada esta, y haciéndose aquellas preponderantes con el mayor número de sus individuos, la atacarían furiosamente hasta lograr su exterminio, se levantarían en masa, tomarían las armas, harían correr arroyos de sangre humana, y no contentos con destruir los templos, en que damos religioso culto al Dios Eterno, se dirigirían a derribar el trono de nuestro político gobierno, para que, siendo víctima de su furor el que dignamente lo ocupase, poder con mayor libertad erigir otro más análogo, y protector de sus falsas religiones". Tal era el sombrío pronóstico que le esperaba a Chile si establecía la tolerancia de cultos frente a los protestantes, advertía el sacerdote (Guzmán, 1822: 12, 20-21).

Volviendo a la polémica intelectual entablada entre Vera y Pintado y Tadeo Silva, para quien significativamente las ideas del primero sobre todos estos tópicos "huelen a protestantismo" (Silva, 1823a: 43), un tercer momento dentro de este debate fue entendido como la consecuencia lógica de los dos momentos argumentales anteriores. En efecto, si de acuerdo a la perspectiva de Bernardo de Vera y Pintado los terremotos eran fenómenos naturales, y que por tanto no respondían a causas teológico-morales, entonces las prácticas devocionales que se habían observado en la población a propósito del sismo del 19 de noviembre carecían de todo sentido y utilidad. "Cuidemos de huir de las paredes y las vigas: y no creamos que con sangre haremos que el sol no queme, o que la tierra inflamada no se mueva", aconsejaba. Aquí Vera y Pintado establecía una crítica anticlerical formidable. Para el santafesino, lo que había quedado en evidencia con la catástrofe era la extensa y profunda influencia del clero en las costumbres de la población chilena, lo que sintetizaba bajo la fórmula del "hábito servil de obedecer" por parte de los ciudadanos y "la suspicacia de los fanáticos" por otra, bajo la cual lograban mantener su hegemonía cultural sobre la población. En otro texto que respondía a los argumentos de Silva, Vera y Pintado avanzó más sobre esta idea, al sostener que el fanatismo clerical que dominaba a la población chilena había terminado creando durante el terremoto "un Dios Cuco para tener en eterno susto al género humano" (Vera y Pintado, 1823: 4). La excesiva influencia social e intelectual del clero dificultaba precisamente el tránsito hacia la modernidad, hacia la conformación de una masa ciudadana virtuosa e ilustrada, condición sine qua non para el establecimiento de una república a la altura de los progresos políticos y técnicos del siglo XIX. De esta forma, continuar interpretando el terremoto como cólera divina significaría no solamente "degradar a la Divinidad", sino también rebajar "el estado de las luces de nuestros conciudadanos, confundiéndolos con los antiguos 
bárbaros Araucanos que atribuían la razón suficiente de todas sus desgracias al Guecuvu o mal principio". El hecho mismo de estar discutiendo el origen propiamente natural de los terremotos en la segunda década del siglo XIX y desde la prensa -"el barómetro de la ilustración o ignorancia de los pueblos"evidenciaba vergonzosamente para Vera y Pintado cuán atrasado estaba el país en su civilización (El Mercurio de Chile, 16-XII-1822).

Fray Tadeo Silva, por su parte, respondiendo a estos argumentos manifestó su sorpresa ante el "furor antievangélico" que se colegía de lo expuesto por Vera y Pintado. Las múltiples manifestaciones rituales ofrecidas por los fieles chilenos para aplacar la furia divina no merecían mayor explicación para el religioso, dado que prácticas tales como "las rogativas públicas, los cilicios, los ayunos y demás obras aflictivas" siempre habían sido usadas por la "indefectible madre Iglesia en ocurrencias de esta clase", prácticas que además concordaban con los ejemplos veterotestamentarios. Lo que era novedoso para el sacerdote no eran tales prácticas, sino su crítica, que evidenciaba "la temeridad y la soberbia de algunos, que se suponen literatos, y que sin embargo desaprueban estas acciones religiosas contra el juicio de tantos personajes autorizados en uno y otro testamento, contra la práctica de todas las ciudades católicas de todos los siglos, y contra el sentir de toda la Iglesia militante" (Silva, 1823a: 6). Las múltiples prácticas mortificantes llevadas a cabo por los feligreses a los que hemos hecho alusión en las páginas precedentes eran vistas de forma positiva por el sacerdote. La reprobación de tales prácticas de parte de "un corto número de irreligionarios" se basaban, como notó Tadeo Silva, en el falso y blasfemo aserto de que si los pecados nada tenían que ver con las catástrofes, siendo entonces "una estupidez entregarse por ellos al ejercicio de obras santas, como si ellas hubiesen de calmar los sacudimientos de este globo". Como ya se apuntó anteriormente, esta idea no solo era falsa desde sus presupuestos, sino que también los críticos a las penitencias y mortificaciones colectivas obviaban el efecto positivo que ellas habían tenido en la moralidad pública: "¿A qué fin, pues, impedir estas lágrimas, estas penitencias, y estas misiones saludables, si los efectos que producen son tan suaves a una conciencia arrepentida? ¿Acaso la predicación y las rogativas a los Santos trastornan el orden establecido por las leyes? ¿Causan el más pequeño mal contra el sistema de nuestra Independencia? ¿Será mal para la sociedad la conversión de tantos malos padres que tenían abandonada la educación de su familia; de tantas mujeres que consumían sus rentas en las vanísimas vanidades de indecentes modas, y de tantos hijos prostituidos a una vergonzosa ociosidad?", se preguntaba el clérigo (Silva, 1823a: 8-9).

Pero no solo esto, sino que además Silva defendió a los penitentes. Si bien la práctica podía llegar a excesos y en ocasiones daba pie a desórdenes -lo que explicaba su supresión durante el gobierno colonial-, en realidad, en casos extremos como el del terremoto resultaban ser acciones "tan pías como 
edificantes". Históricamente los feligreses católicos habían actuado de este modo, y no debía suspenderse en la actualidad solo porque tal práctica les resultara chocante a "los filósofos de la edad presente". Asimismo, importaba poco que la autoflagelación de unas "espaldas delincuentes" afectase la salud y las emociones femeninas, cuando en realidad las féminas de la capital pasaban sus noches en bailes y meriendas, agregando que "las mismas damas se martirizan hasta el extremo por el diablo, e impiden la circulación libre de la sangre con los jubones con que se ciñen, y las tablas con que se empalan para andar derechas en el baile, y contra estos vicios que acaban con el sexo débil haciéndole contraer mil males físicos y morales no se dice una sola palabra; solo un miserable penitente se hace el objeto de sus declamaciones porque con su vista atemoriza al sexo hermoso", ironizaba (Silva, 1823a: 46-47). No menos irónica fue la respuesta de Vera y Pintado, cuando en su Palinodia replicó con sorna: " ¡Maldito sea este flujo de ver las leyes, y que por mis pecados topase con la cédula de Carlos $3^{\circ}$ condenando los empalados y disciplinantes, en vez de haber buscado alguna que condenase al fraile que haga abortar a las mujeres de susto, y morir los hombres a fuerza de látigos y palos pesados! Porque ya se ve, estas cosas son tan bonitas, tan útiles a la Religión y a la humanidad, que necesitan de una ley expresa para proscribirse; y cuando la Iglesia y la policía han reprobado el exceso de las penitencias, no comprendieron seguramente estos saludables efectos nacidos de ese exceso" (Vera y Pintado, 1823: 10).

\section{Reflexiones finales}

Como hemos visto, el terremoto de 1822 permitió develar el conflicto entre dos mentalidades. Desde la perspectiva del racionalismo las prácticas devocionales que la sociedad afectada por la catástrofe había desplegado para conjurar las fuerzas naturales y aplacar la ira divina eran propias de una visión de mundo que los conocimientos científicos de la llustración ya habían superado. ${ }^{10}$ Prácticas religiosas como las que hemos analizado en estas páginas, evidenciaban para autores como Camilo Henríquez y Bernardo de Vera y Pintado el negativo legado del mundo colonial que aún pesaba sobre la sociedad chilena, particularmente en lo que se refiere a los atributos intelectuales de la población, aún sometida a la ignorancia, superstición y a la influencia incontrastable del clero, fenómenos que explicaban el dificultoso tránsito hacia una sociedad moderna, precisamente el proyecto cultural y político por ellos defendido. ${ }^{11}$ Esta postura, no obstante, debe ser leída no

10 Sobre este problema en Europa, véase el clásico trabajo de Hazard (1952).

11 Sobre el contenido modernizador de la llustración de fines del siglo XVIII en América, véase Chiaramonte (1990). Para el caso chileno, véase Jocelyn-Holt (2001: 99-118). 
como un ataque a la religión -lo que resulta evidente, por ejemplo, en el caso de Camilo Henríquez- sino más bien en una perspectiva de crítica anticlerical. Es decir, el punto en cuestión era el excesivo ascendiente cultural del clero en las mentalidades, lo que explicaba la persistencia de prácticas fundadas en lo que se denominaba "supersticiones" y "fanatismo", lo que posibilitaba espectáculos tan chocantes como las autoflagelaciones. Así, lo que se buscaba no era la exclusión de la fe como medio de consuelo ante las catástrofes naturales, sino que la devoción fuese interiorizada por una piedad más privada y recatada, en lugar de los excesos a los que daba pie la exterioridad barroca y que se hacían patentes en situaciones límites como esta. ${ }^{12}$ En este sentido, estas polémicas intelectuales evidencian una línea de continuidad clara entre el ideario iluminista dieciochesco y sus querellas contra la piedad barroca en el mundo colonial, y su pervivencia en el contexto post-independentista.

Desde la vereda contraria, lo que habían demostrado las actitudes generalizadas de la población chilena con ocasión del terremoto era precisamente la vigencia de la devoción barroca y la hegemonía de la Iglesia católica en la explicación del funcionamiento del orden natural, que en modo alguno estaba separado del orden moral. La extensión de la visión providencialista del mundo físico había sido consagrada con las prácticas de los aterrorizados feligreses. Fue desde esta posición que sacerdotes como Tadeo Silva salieron a defender esta visión de mundo en la incipiente esfera pública nacional, combatiendo de esta forma a quienes cuestionaron la tutela eclesiástica sobre las conciencias de la población. Tal cuestionamiento explícito precisamente explicaba, desde la perspectiva de Silva, en parte la causalidad de la tragedia, entendida como la justa retribución divina ante la creciente pecaminosidad y libertinaje intelectual que se reflejaba en la cultura ilustrada chilena. El hecho de referirse a sus contendientes intelectuales bajo rótulos tan significativos como "irreligionarios", "defensores del naturalismo", "filósofos de la edad presente" y "filósofos de moda", representaba para el sacerdote uno de los desafíos más importantes para el clero nacional, quienes debían salir a defender su visión de mundo pero no desde las lógicas argumentativas que la impiedad racionalista exigía, sino desde las antípodas, desde la perspectiva de un "filósofo rancio" -como se autodenominó- que fundaba sus argumentos desde la incuestionable autoridad de "la Santa Escritura y los testimonios de los Santos Padres de la Iglesia" (Silva, 1823a: 52).

Pero además, el terremoto de noviembre de 1822 evidencia de forma clara el uso político de las catástrofes, una cantera muy rica de análisis desde la

12 Para este mismo debate en el caso del terremoto de 1746 en Lima, véase el trabajo de Walker (2008). 
historia de las mentalidades, como aconsejaba Rolando Mellafe (1994: 117). No era por cierto la primera vez que se daba esta situación en Hispanoamérica en el siglo XIX, y los usos realistas del terremoto de 1812 en la coyuntura independentista de Venezuela es quizás uno de los casos más paradigmáticos de esta situación (Rodríguez, 2010). El terremoto de 1822 representó para el gobierno de O'Higgins no solo una catástrofe que implicaba trabajar en la reconstrucción, sino también se convirtió en una fuente de críticas a su administración. Mary Graham (1824: 312-313) recordó que más de alguien sugirió que la catástrofe era una señal del enojo celestial ante el autoritarismo de su mandato, aunque la mayor parte de la población la atribuyó hacia la política tolerante hacia los protestantes del Director Supremo. Con todo, el terremoto fue un nuevo frente de ataque que contribuiría a socavar las bases de legitimidad del héroe independentista, que finalmente terminaría abdicando semanas después, en enero de 1823.

\section{Referencias bibliográficas}

\section{Fuentes primarias}

\section{a.- Documentales}

Archivo Nacional, Fondo Ministerio del Interior, Vol. 22

\section{b.- Periódicos}

El Argos de Chile, Santiago de Chile, 1818

Gazeta Ministerial de Chile, Santiago de Chile, 1819-1822

Niles' Register, Baltimore, 1823

El Mercurio de Chile, Santiago de Chile, 1822-1823

\section{C.- Impresos}

Bladh, C. E. (1951), La República de Chile 1821-1828. Santiago: Imprenta Universitaria.

Cid, G. (2009). El Mercurio Chileno. Santiago: DIBAM/Centro de Investigaciones Diego Barros Arana.

Graham, M. (1824). Journal of a residence in Chile, during the year 1822. Londres: Longman and Co.

Guzmán, J. (1822). Dictamen que a petición del Gobierno da el provincial de S. Francisco sobre la introducción de los extrangeros en Chile. Santiago: Imprenta de D. Esteban Valle. 
Haigh, S. (1831). Sketches of Buenos Ayres, Chile and Peru. Londres: Effingham Wilson

Longeville Vowell, R. (1831). Campaigns and cruises in Venezuela and New Grenada, and in the Pacific Ocean; from 1817 to 1830. Londres: Longman and Co., vol. I.

Miers, J. (1826). Travels in Chile and La Plata. Londres: Baldwin, Cradock and Joy, vol. I.

Pérez Rosales, V. (1962). Recuerdos del pasado. Barcelona: Iberia.

Miquel, J. (1849). "Apuntes sobre el terremoto de 1822", en Revista de Santiago, t. III, p. 105-111.

Silva, T. (1823a). Aviso que da al pueblo de Chile un filósofo rancio. Santiago: Imprenta Nacional.

Silva, T. (1823b). Los apóstoles del diablo. Santiago: Imprenta Nacional.

Thurn, C. (1919). "Terremoto del 19 de noviembre de 1822. Informe dirigido al señor Brigadier y Gobernador de la Plaza de Valparaíso, don José Ignacio Zenteno, por don Carlos Thurn", en Revista Chilena de Historia y Geografía, № 31, p. 189-193.

Vera y Pintado, B. (1823). Palinodia del consolador en satisfacción al filósofo rancio. Santiago: Imprenta Nacional.

Vergara Quiroz, S. (1987). Cartas de mujeres en Chile 1630-1885. Santiago: Editorial Andrés Bello.

\section{Fuentes secundarias}

Álvarez, E. (2005). "Leibniz damnificado por el terremoto de Lisboa", en Cuadernos Dieciochistas, Vol. 6, p. 187-201.

Burke, P. (1978). Popular Culture in Early Modern Europe. Nueva York: Harper Torchbook.

Castillo, C. (2005). "Una propiedad sin vida: secularización de los bienes de regulares en Chile (1767-1842)", en Claudia Castillo et al., Seminario Simon Collier 2005. Santiago: Instituto de Historia Pontificia Universidad Católica de Chile, p. 11-41.

Chiaramonte, J. (1990). "Ilustración y modernidad en el siglo XVIII hispanoamericano", en Ricardo Krebs y Cristián Gazmuri, eds., La Revolución Francesa y Chile. Santiago: Editorial Universitaria, p. 83-109. 
Delumeau, J. (2002). "Miedos de ayer y hoy", en Jean Delumeau et al., El miedo. Reflexiones sobre su dimensión social y cultural, Medellín, Corporación Región, pp. 9-21.

Di Stefano, R. (2004). El púlpito y la plaza. Clero, sociedad y política de la Monarquía católica a la República Rosista. Buenos Aires: Siglo XXI.

Dynes, R. (2000). "The dialogue between Voltaire and Rousseau on the Lisbon earthquake: The emergence of a Social Science view", en International Journal of Mass Emergencies and Disasters, Vol. 18, № 1, p. 97-115.

Fernández Sebastián, J. (2011). "'Cabalgando el corcel del diablo'. Conceptos políticos y aceleración histórica en las revoluciones hispánicas", en Javier Fernández Sebastián y Gonzalo Capellán de Miguel, eds., Lenguaje, tiempo y modernidad. Ensayos de historia conceptual, Santiago: Globo Editores, p. 21-59.

Ginzburg, C. (1994). "Microhistoria: dos o tres cosas que sé de ella", en Manuscrits, № 12 , pp. 13-42.

Góngora, M. (1998). Estudios sobre la historia colonial de Hispanoamérica. Santiago: Editorial Universitaria.

Hazard, P. (1952). La crisis de la conciencia europea (1680-1715). Madrid: Pegaso.

Jocelyn-Holt, A. (2001). La Independencia de Chile. Tradición, modernización y mito. Santiago: Planeta/Ariel.

Koselleck, R. (2004). Futures past. On the semantics of historical time. New York: Columbia University Press.

Levi, G. (1996). "Sobre la microhistoria", en Peter Burke, ed., Formas de hacer historia. Madrid: Crítica, p. 119-143.

Mellafe, R. (1994). La memoria de América colonial. Santiago: Editorial Universitaria.

Paice, E. (2008). Wrath of God: the great Lisbon earthquake of 1755. London: Quercus.

Palacios Roa, A. (2009). "El gran terremoto de 1730", en Temas Americanistas, $N^{\circ} 22$, p. 1-18

Rodríguez, P. (2010). "Miedo, religión y política: a propósito del terremoto de 1812", en Revista de Historia Social y de las Mentalidades, Vol. 14, № 2, p. 237-260.

Sanides-Kohlrausch, C. (2003). "The Lisbon earthquake, 1755. A discourse about the 'nature' of nature", en Willem B. Drees, ed., Is Nature Ever Evil?: Religion, Science, and Value, New York, Routledge, p. 106-199. 
Serna, J. y Pons, A. (2000). Cómo se escribe la microhistoria: ensayo sobre Carlo Ginzburg. Madrid: Cátedra.

Shrady, N. (2009). The Last Day: Wrath, Ruin, and Reason in the Great Lisbon Earthquake of 1755. New York: Penguin.

Valenzuela, J. (1995). "Aspectos de la devoción barroca en Chile colonial", en Colonial Latin American Historical Review, Vol. 4, N³, p. 261-286.

Valenzuela, J. (2006). "El terremoto de 1647: experiencia apocalíptica y representaciones religiosas en Santiago colonial", en Jaime Valenzuela, ed., Historias urbanas. Homenaje a Armando de Ramón. Santiago: Ediciones Universidad Católica de Chile, p. 27-65.

Vicuña Mackenna, B. (1939). Obras completas. Discursos Parlamentarios, I, Santiago: Universidad de Chile.

Vicuña Mackenna, B. 1976 [1861]. Vida del Capitán General don Bernardo O'Higgins. Santiago: Editorial del Pacífico.

Walker, C. (2008). Shaky Colonialism. The 1746 Earthquake-Tsunami in Lima, Peru, and its Long Aftermath. Durham: Duke University Press. 